\title{
DETERMINANTS OF EFFECTIVENESS OF STAY-AT-HOME AGAINST COVID-19
}

\author{
Harun Öztürkler ${ }^{\mathrm{a}}$, Burçhan Sakarya ${ }^{\mathrm{b}}$, Bedri Kamil Onur Taş ${ }^{\mathrm{c}}$, \\ ${ }^{a}$ Kırıkkale University, Department of Econometrics \\ ${ }^{b}$ Presidency of the Republic of Turkey, Strategy and Budget Office \\ 'TOBB Economy and Technology University, Department of Economics and Department \\ of Artificial Intelligence Engineering
}

\begin{abstract}
Quarantines are basic public health policies against pandemics. The wide spread quarantines worldwide against Covid-19 have been dubbed as "great lockdown" as a reference to the great depression in 1929. While quarantines may save millions of lives by limiting the mobility of people and isolating infected individuals, they also result in massive economic disruptions. Therefore, quarantine policies must be science-based policies, which requires comprehensive knowledge about the mode of interactions among the members of the society. In addition, quarantines must be inclusive in the sense that it must treat different segments of the society equally. In case of the Covid-19 instances in the US, we observe that the effectiveness of stay-at-home measures vary intensely across the states. Therefore, we hypothesize that prevailing factors such as population density and mode of transportation might play the key role in the differences in effectiveness of stay-at-home measures. Utilizing differencesin-differences estimation methodology, we inspect the impact of changes in mobility and structural factors such as modes of transportation and population density on Covid-19 cases in the US. Our findings show that restricting mobility and implementing stay-at-home measure significantly lower Covid-19 cases. In addition, the states with lower vehicle ownership have considerably higher cases. Population density also plays an important role as higher population density causes higher infection and cases.
\end{abstract}

JEL Classification: C50, D70, E70, H7

Key Words: Covid-19, Restricted Mobility, Stay-at-Home, Vehicle Ownership, Population Density

The Covid-19 Riddle: Why Does the Virus Wallop Some Places and Spare Others? New York Times, By Hannah Beech, Alissa J. Rubin, Anatoly Kurmanaev and Ruth Maclean, May 3, $2020^{1}$

\section{Introduction}

One of the defining characteristics of the current Covid-19 health and economic crises humanity facing is uncertainty. The causes and speeds of spread of infection are heterogeneous even among the neighboring places. Duration of this pandemic is still unknown as it is not foreseeable when a vaccine will be available even under ideal circumstances. The economic consequences of the pandemic also depend on many conflicting factors. A delay in the availability of a cure and/or a vaccine can result in significant human and economic losses.

\footnotetext{
${ }^{1}$ Available online at https://www.nytimes.com/2020/05/03/world/asia/coronavirus-spread-wherewhy.html?action=click\&module=Spotlight\&pgtype=Homepage.
} 
Furthermore, the history teaches us that vaccines come too late to have a substantial preventive power in terms of human and economic losses. Therefore, until we have a vaccine that provides a neutralizing immune response, it is crucial to control the spread of virus, which requires a detailed knowledge of what contributes to its transmission.

On the basis of this background, this paper starts with the observation that the Covid-19 cases and effectiveness of stay-at-home measures differ dramatically across United States (US). For instance, as it can be observed from Figure 1 below, for many states starting to endorse stay-athome measures almost at the same time, the paths of weekly number of cases differ significantly. We detect divergent paths even after controlling for the population density, as in the case of New York and California. On the other hand, there are examples of cases that even when the timing of implementation of stay-at-home measures differ substantially, as in the cases of Florida and California, the time paths of the number of weekly cases are similar. Therefore, we argue that structural factors such as population density and mode of transportation might play a role in the effectiveness of stay-at-home measures. In this paper we empirically examine these factors.

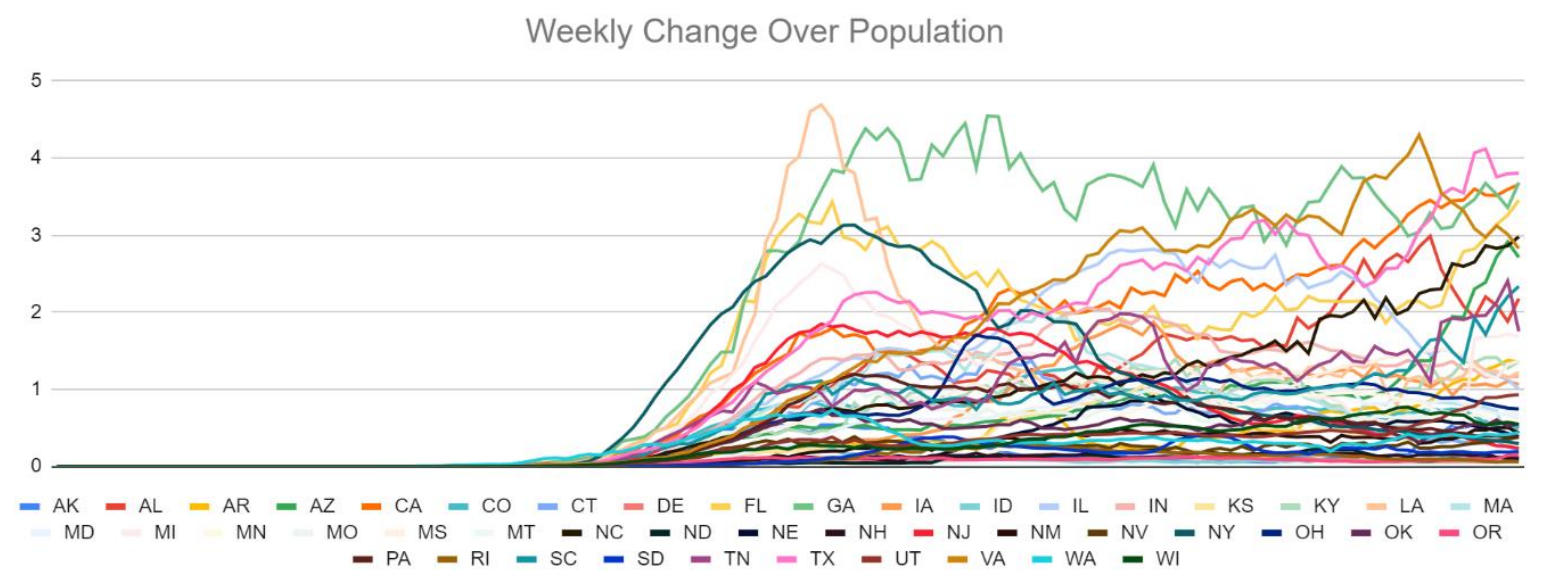

Figure 1: Weekly Change per 1000 residents

We implement a differences-in-differences methodology to examine the impact of changes in mobility and structural factors such as modes of transportation and population density on Covid-19 cases in the US. US provides an excellent research platform since states employ significantly different policies to cope with Covid-19. Additionally, states have fundamental differences in terms of modes of transportation and population densities. Since Federal policies prevented international travel for all states simultaneously, we can identify the impact of mobility and structural state-specific factors. Figure 2 below displays the significant differences across states. 
0.6

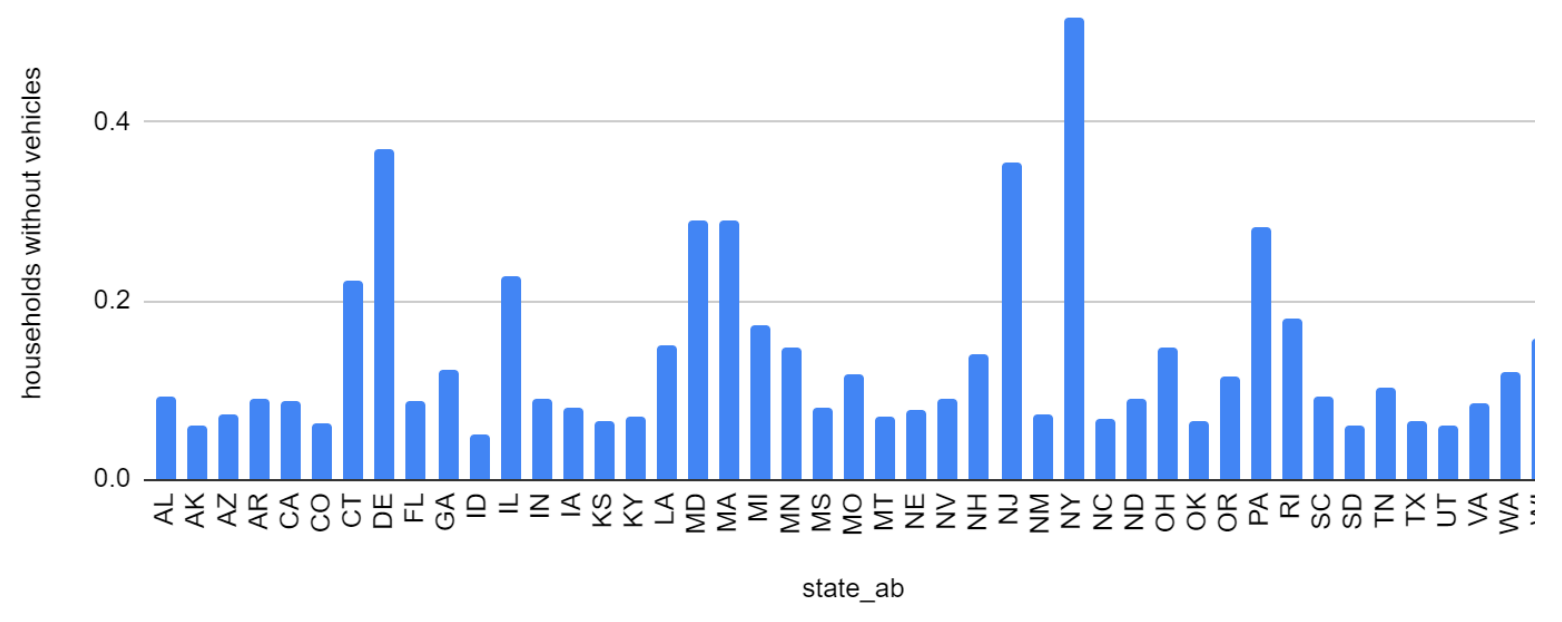

Population per Square Mile vs. state_ab

25000

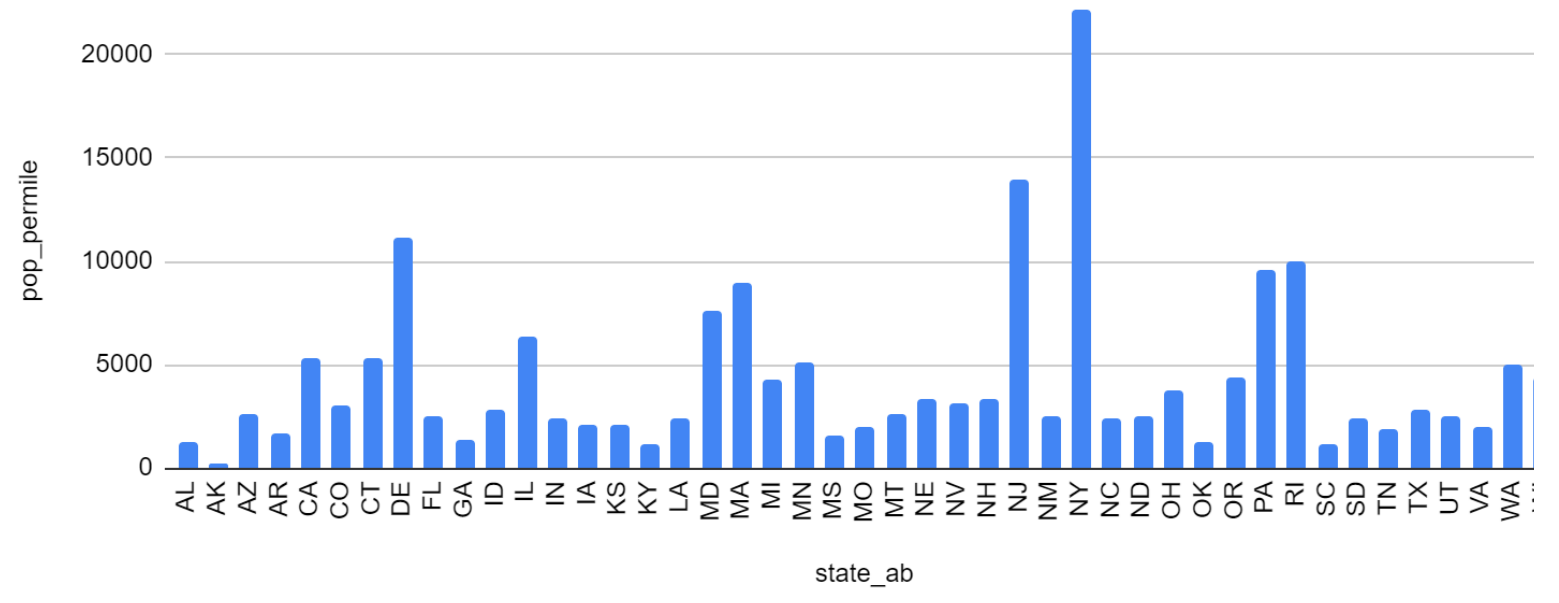

Figure 2: Transportation and Population in US States

Empirical analyses in Section 3 conclude that declining mobility and spending more time in residential places significantly decrease Covid-19 cases. Additionally, we find that using private vehicles for transportation decreases cases, while higher population density contributes to increases in cases.

\section{Recent Literature}

Covid-19 outbreak has already started to cause an unprecedented bearing on every facet of the human life that threatens to reshape the global economic, social and political world order. For a better understanding of how the Covid-19 virus spreads, and how proper public policies can be designed to contain it, we need an enhanced knowledge about the causal effects behind the spread of the virus. Most importantly, the knowledge of how the Covid-19 spreads is crucialfor preparing for the possible future pandemics. Alverez et al. (2020) points out the fact that the 
optimal policy critically depends on the fraction of susceptible and infected in the population, and therefore, on the mode and intensity of social interactions. As pointed out by Acemoglu et al. (2020), not only different subpopulations typically have different risks but also they may interact with other subpopulations at different rates. Furthermore, the ways that different subpopulations interact with other subpopulations differ significantly. Therefore, Acemoglu et al. (2020) argue that policies differentially targeting to regulate the interaction among subpopulations outperform uniform policies in terms of minimizing both infections and deaths and economic losses.

Not only countries but also states and cities in a given country may follow different quarantine policies. As stated by Berger et al. (2020), quarantine policy is case-dependent. Furthermore, Wang et al. (2020) calls attention to the fact that a very high infection rate and an extremely infectious incubation period make the control of Covid-19 through a quarantine policy without a proper knowledge about the interaction behavior of the population a considerably difficult task. On the other hand, as economists in Baldwin and Mauro (2020a)'s collection assess in a variety of ways how deeply Covid-19 effects economies around the world in both real and financial spheres, the degree and longevity of economic shocks depend on the extend of lock down together with uncertainties surrounding the disease. Uncertainties alter the behavior of both consumers and producers as well as policy makers. It proves once again that knowledge of the channels of transmission of virus is crucial for understanding behavioral changes of economic decision makers.

Dave et al. (2020) explore the impact of shelter in place orders (SIPO), with particular attention to heterogeneity in their impacts. However, they document that at adoption of a SIPO was associated with only a 5 to 10 percent increase in the rate at which state residents remained in their homes fulltime. Even with a small increase in stay at home they find a significant cumulative decline in covid-19 cases. Furthermore, SIPO-induced case reductions grew larger over time although there is important heterogeneity across states - early adopters and high population density states appear to reap larger benefits from their SIPOs.

Research on the economic effects of the Covid-19 provides insightful findings and makes valuable policy recommendations. Stephany et al. (2020) remind that research based on the historical data manifests that there is a correlation between mortality from viruses and declines in gross domestic product (GDP) and rise in poverty rates. Moreover, although the degree of globalization we have today makes historical comparisons dubious, we can claim that today's interconnectedness escalates both pandemic diseases and their economic consequences. This assessment is even more relevant for the US, where connectedness can be considered as almost complete. For instance, Eichenbaum et al. (2020) show that simple containment policies that reduce consumption and hours worked exacerbate the recession but recession raises welfare by reducing the death toll caused by the epidemic in the US. In their benchmark model when vaccines and treatments do not arrive before the epidemic is over and healthcare capacity is limited, containment policy saves roughly half-a-million lives in the US.

Keogh-Brown et al. (2010), in their study on of the United Kingdom, France, Belgium and The Netherlands for the case of the outbreak of severe acute respiratory syndrome (SARS) in 2003, argue that while it is important that appropriate measures are taken to minimize the impacts of the pandemic, these measures can be costly. Furthermore, they contemplate that a more widespread pandemic would be even more costly that the case of SARS. They suggest that 
careful planning is therefore important to ensure expensive policies to mitigate the impacts of pandemics. On the other hand, it is obvious that a careful planning necessitates full information regarding all aspects of the pandemic.

Farboodi et al. (2020) integrate privately optimal behavior and policy analysis into an epidemiological model. Their findings suggest that while individuals gradually reduce social activity due to risk of infection, an optimal policy immediately curtails social activity in order to delay the full outbreak and buy time. Therefore, the spread of the pandemic depends crucially how the society and individuals react during the time interval between the start of outbreak and policy curtails. Especially the mode and intensity of interactions among the individuals ordinarily determine the course of pandemic. As shown by Pindyck and Wang (2013), how society will behave will be shaped by how much individuals are willing to pay to limit the health risk and reduce the impact on the economy. On the basis of their calculations of "willing to pay" and argument that governments with their short political cycles have the tendency to underestimate both the likelihood and possible impact of catastrophic events they suggest that governments should devote greater resources to reducing the risk and potential impact of catastrophes, including pandemics caused by megaviruses. As Otsu (2009) emphasizes, pandemic preparedness requires continuously improved and multi-stages and multi-sectors plans involving central and local governments.

By studying the value of government commitment in choosing a lockdown policy, Moser and Yared (2020) conclude that the optimal policy under government commitment trades off the aggregate output cost with the health benefits. However, the effectiveness of measures will depend on various factors such as the type and the size of containment area, size of the population, channels of the provision of basic materials and services, and most importantly the channels and intensity of interactions among the individuals.

Jorda et al. (2020) study 15 major pandemics where more than 100,000 people died, using a dataset stretching back to the 14th century. They find that significant macroeconomic aftereffects of the pandemics persist for about 40 years. In a similar vein, Long (2010) argues that global economic and political stability could fall victim to a pandemic, which can stress and overwhelm a state's capacity to meet its essential functions. When considering the current pandemic with its scale death toll, it is reasonable to assume a similar macroeconomic impact. Therefore, it is our contention that in order to minimize health and economic consequences of pandemics it is crucial to be prepared, which requires detailed and dynamic planning and collaboration between governments and between government and society. Among other things, such a planning process naturally requires comprehensive knowledge of structural constructs of societies and economies and how individuals behave in different settings. Hence, in this paper we empirically study these factors and try to assess effectiveness of containment policies. Such an assessment will also compel us to think about how people and the economy will adjust in a post-pandemic world.

\section{Data, Model, and Estimation Result}

We obtain daily US county level data on COVID-19 cases from the Johns Hopkins University Center for Systems Science and Engineering (CSSE) data repository. ${ }^{2}$ County-level mobility

\footnotetext{
${ }^{2}$ Data is updated daily and available online at https://github.com/CSSEGISandData/COVID-19.
} 
data is available at Google. ${ }^{3}$ We examine daily data of US counties for 22 January 2020-5 June 2020 time period. We employ the following state specific factors to determine the structural factors that lead to significant differences across states in COVID-19 cases: car ownership and population density. We obtain these data from The National Weather Service (NWS) compiling regional data under The Applied Climate Information System (ACIS) Project. This data is available at The NWS NOWData site. ${ }^{4}$ We measure automobile ownership as percentage of households without vehicles and population density as population per square-mile.

Google mobility data reports information about daily changes in visits to retail and recreation, grocery and pharmacy, transit stations, work places and residential places.

We use the following difference-in-difference specification to analyze the impact of changes in mobility and state-specific factors.

$$
\Delta C 19_{s, t}=\beta_{0}+\beta_{1} \Delta M_{s, t}+\beta_{2} \operatorname{Car}_{s}+\beta_{2} \operatorname{Pop}_{s}+\varepsilon_{s, t}
$$

where $\Delta C 19_{s, t}$ is the weekly change in COVID-19 cases in US state $s . \Delta C 19_{s, t}$ is normalized with state population. The CSSE present information in county level. We sum county COVID19 cases for each state since we use additional state-level variables. $\Delta M_{s, t}$ represents weekly change in mobility measures (on retail \& recreation, grocery \& pharmacy, parks, transit stations, workplaces or residential) in state $s$ at time $t$. Table 1 displays the estimation results with alternative mobility measures.

\footnotetext{
${ }^{3}$ Data is updated daily and available online at https://www.google.com/covid19/mobility/.

${ }^{4} \mathrm{https}$ ///w2. weather.gov/climate/xmacis.php?wfo=cle
} 
Table 1: Effects of Mobility and State Specific Factors on COVID-19 Cases

\begin{tabular}{lccccc}
\hline Variable & 1 & 2 & 3 & 4 & 5 \\
\hline retail_and_recreation & 0.01 & & & & \\
& $(22.97)^{* *}$ & & & & \\
grocery_and_pharmacy & & 0.003 & & & \\
& & $(5.20)^{* *}$ & & & \\
transit_stations & & & 0.013 & & \\
& & $(23.54)^{* *}$ & & 0.009 \\
workplaces & & & $(14.46)^{* *}$ & \\
& & & & -0.029 \\
residential & & & & & $(22.12)^{* *}$ \\
& & & & & \\
Households Without vehicles & 1.406 & 1.403 & 1.449 & 1.415 & 1.421 \\
& $(6.92)^{* *}$ & $(6.64)^{* *}$ & $(7.19)^{* *}$ & $(6.85)^{* *}$ & $(7.00)^{* *}$ \\
Population per Square mile & 0.030 & 0.029 & 0.030 & 0.029 & 0.029 \\
& $(4.75)^{* *}$ & $(4.45)^{* *}$ & $(4.75)^{* *}$ & $(4.50)^{* *}$ & $(4.63)^{* *}$ \\
Constant & 0.061 & 0.055 & 0.063 & 0.069 & 0.067 \\
& $(5.01)^{* *}$ & $(4.39)^{* *}$ & $(5.30)^{* *}$ & $(5.69)^{* *}$ & $(5.57)^{* *}$ \\
\hline $\mathrm{R}^{2}$ & 0.30 & 0.25 & 0.31 & 0.28 & 0.30 \\
No of Observations & 4,725 & 4,725 & 4,725 & 4,725 & 4,725 \\
\hline
\end{tabular}

Notes: $*$ and $* *$ represent significance at $5 \%, 1 \%$ respectively. Robust Standard errors are in parentheses.

The results reported in Table 1 indicate that restricting mobility and being at residential places causes significantly lower COVID-19 cases. Furthermore, the states with lower vehicle ownership have significantly higher cases. Population density also plays an important role as higher population density causes higher infection and cases.

\section{Conclusion}

Covid-19 poses a grievous health and economic crises for countries all over the world. The wide spread quarantines worldwide against the virus have been dubbed as "great lockdown" as a reference to the great depression in 1929 (see IMF, 2020). Covid-19 pandemic also constitutes an unprecedented challenge for public health and socio-economic policy making. A comprehensive and synchronized policy combination is necessary to deal with health and socioeconomic consequences of the crisis. Such a policy making with an immense number of dimensions requires all-inclusive knowledge of underlying causes and effects relations among those dimensions. A look at the US demonstrates that causal relations in the transmission mechanism of the covid-19 display major variations between the states. Therefore, economic costs and necessary measures deviate from state to state. Hence, in order to find an underlying reason for these deviances, we conjecture that factors such as population density and mode of transportation might play a key role in the spread of the virus. We utilize the differences-indifferences estimation methodology and find that restricting mobility and implementing stayat-home measure significantly lower Covid-19 cases in the US. Moreover, the states with lower vehicle ownership have considerably higher cases. We further determine that population density plays an important role as higher population density causes higher infection and cases. As a result, we recommend that mobility, mode of transportation and population density should be incorporated in designing precautionary policies against covid-19.

\section{References}


Acemoglu, Daron., Victor Chernozhukov, Iván Werning, and Michael D. Whinston. (2020), A Multi-Risk Sir Model with Optimally Targeted Lockdown, NBER, Working Paper 27102.

Alvarez, Fernando E., David Argente, and Francesco Lippi. (2020), A Simple Planning Problem for Covid-19 Lockdown, NBER, Working Paper 2698.

Baldwin, Richar., and Beatrice Weder di Mauro. (2020), Mitigating the COVID Economic Crisis: Act Fast and Do Whatever It Takes, VoxEU.org eBook, CEPR.

Berger, David W., Kyle F. Herkenhoff , and Simon Mongey. (2020), An SEIR Infectious Disease Model with Testing and Conditional Quarantine, NBER, Working Paper 26901.

Dave, Dhaval M., Andrew I. Friedson, Kyutaro Matsuzawa, and Joseph J. Sabia. (2020), When Do Shelter-in-Place Orders Fight Covid-19 Best? Policy Heterogeneity Across States and Adoption Time, NBER, Working Paper 27091.

Eichenbaum, Martin S., Sergio Rebelo, and Mathias Trabandt. (2020), The Macroeconomics of Epidemics, NBER, Working Paper 26882.

Farboodi, Maryam., Gregor Jarosc, and Robert Shimer. (2020). Internal and External Effects of Social Distancing in a Pandemic, NBER, Working Paper 27059.

IMF. (2020). World Economic Outlook, April 2020: The Great Lockdown, International Monetary Fund, Washington DC, https://www.imf.org/en/Publications/WEO/Issues/2020/04/14/weo-april-2020

Jordà, Òscar., Sanjay R. Singh, and Alan M. Taylor. (2020). Longer-Run Economic Consequences of Pandemics, NBER, Working Paper 26934.

Keogh-Brown Markus Richard., Richard D. Smith, John W. Edmunds, and Philippe Beutels. (2010), The Macroeconomic Impact of Pandemic Influenza: Estimates from Models of the United Kingdom, France, Belgium and The Netherlands. The European Journal of Health Economics, 11(6), 543-554. doi:10.1007/s10198-009-0210-1

Long, William J. (2010). Pandemic Preparedness: A US Strategy for Infectious Disease Control, US Institute of Peace, https://www.jstor.org/stable/resrep12403.

Moser, Christian A., and Pierre Yared. (2020), Pandemic Lockdown: The Role of Government Commitment, NBER, Working Paper 27062.

Otsu, Satoko. (2009), An Overview of Pandemic Preparedness in the Western Pacific Region, in Pandemic Preparedness in Asia (Editor: Mely Caballero-Anthony), S. Rajaratnam School of International Studies, 8-12, www.jstor.org/stable/resrep05905.

Pindyck, Robert S., and Neng Wang. (2013), The Economic and Policy Consequences of Catastrophes, American Economic Journal: Economic Policy, 5(4), 306-339.

Stephany, Fabian., Niklas Stoehr, Philipp Darius, Leonie Neuhäuser, Ole Teutloff, and Fabian Braesemann. (2020), The CoRisk-Index: A Data-Mining Approach to Identify IndustrySpecific Risk Assessments Related to COVID-19 in Real-Time, http://dx.doi.org/10.2139/ssrn.3607228.

Wang, Pei., Jun-an Lu, Yanyu Jin, Mengfan Zhu, Lingling Wang, and Shunjie Chen. (2020), Epidemiological characteristics of 1212 COVID-19 patients in Henan, China, medRxiv. 